\title{
The Politics of Information on Traditional Medical Practices in Bandung Barat
}

\author{
${ }^{1}$ RULLY KHAIRUL ANWAR, ${ }^{2}$ AGUS RUSMANA, ${ }^{3}$ M. TAUFIK RAHMAN \\ 12 Department of Library and Information Science of Communication Faculty (FIKOM) of \\ Universitas Padjadjaran, Jl. Bandung-Sumedang KM 21 Jatinangor ${ }^{3}$ Department of Sociological Science of Social \\ and Political Science Faculty (FISIP) of Universitas Islam Negeri Sunan Gunung Djati Bandung \\ email: ${ }^{1}$ rully.khairul@unpad.ac.id;²a.rusmana@unpad.ac.id; ${ }^{3}$ fikrakoe@uinsgd.ac.id
}

\begin{abstract}
This study examines the politics of information within organizations or groups of traditional medical practitioners in West Bandung Regency of West Java Province. The political process of information here includes the activities of how the government implements information policies in relation to traditional medicine. The study also learned how traditional medicine groups respond to public policy on traditional medicine. The method used is qualitative with data collection technique through observation, interview, documentation, and literature study. The results show that there is local politics of information distribution activity in West Bandung society marked by the existence of the managers of traditional medicine, patients, the government with its regulations, and other politics of information distribution activities that led to the maintenance of science and traditional medical services. It is clear that the main reason for the politics of information to exist was economic.
\end{abstract}

Keywords: traditional medicine, local knowledge, politics of information

\section{Introduction}

The information society has a primary need to get the information required to support various daily activities and other demands. The need for information is considered to continually growing in someone whenever he/she wants to know something. Similarly, curiosity arises when one wants to add new things to the long list of his knowledge treasures. According to Choo (2016), information needs are driven by a problematic situation where a person feels the need to obtain input from sources outside himself/herself. While Belkin \& Kwasnik (2017) named this as anomalous state of knowledge, one feels that his/her level of knowledge is insufficient to deal with a particular situation at the time.

The rapid development and utilization of information technology (IT) have made IT a driving force for developing society in various fields, thus also implicate to social and economic development at present and in the future. IT gave birth to a new era where the transactions of goods and services are performed by using communication networks with their own symbols, codes, and bureaucracy.

Meanwhile, traditional medical services are still widely used and exist in the society. The tendency to increase the utilization of traditional medicine has led to scientific information related to traditional medicine in an important position, both to become a scientific basis in the usage of traditional medicine by society and company, and as a reference of "state of the art" research of traditional medicine for scientists.

Ideally, all this scientific information, both in print format and electronic files can be obtained from the nearest library. Often this request cannot be fulfilled due to several reasons, one of which is quite a high cost to subscribe the scientific information sources. As an alternative, the Internet is the right choice to be a source of information. Websites as part of the provider of information on the Internet are increasing in number over time. Not only that, the community also has a self-managed network of contacts using

Received: December 04, 2017, Revision: March 20, 2018, Accepted: June 04, 2018

Print ISSN: 0215-8175; Online ISSN: 2303-2499. DOI: http://dx.doi.org/10.29313/mimbar.v34i1.3256.158-165

Accredited B based on the decree No.040/P/2014, valid on February, 18, 2014 until February, 18, 2019. Indexed by DOAJ, Sinta, IPI 
the internet to communicate with each other about this traditional medicine problem. For example is the number of Facebook groups and sites on traditional medicine.

With this huge number of sites, there are many chances for a site to provide information on traditional and related treatments. Because of the importance of the internet which can be a source of information for a study of science (chemistry for example), many authors teach techniques on how to obtain information from the internet as the main material in the course of chemistry information (Brouwer \& McDonnell, 2015).

On the other hand, to response the community's need for traditional medicine, there are governments laws regulate and oversee the development of traditional medication aiming at protecting communities from the harmful effects of traditional medical practices. As an example, there is Government Law no. 103 of 2014 on Traditional Health (Sugyati, et.al. 2017). In order to retort to the government's policy on the development of traditional medicine, the community, especially traditional medication service providers, inevitably have to pay attention to the politics of information, so that their practices are not collided with government regulations. This is where the importance of politics of information in terms of traditional medicine took place.

Meanwhile, in some areas of Indonesia, the provision of public health services is still constrained by the limited amount of budgetary allocations. It happens in West Bandung regency, which is a new district, established in 2007. Therefore, the existence of traditional medicine becomes an alternative for the community as a reference for health treatment. Moreover, the politics of information of traditional medicine has adapted modern information systems such as the internet.

Various researchers related to political policy on health are many, but discussing the politics of information on traditional medicine is rare. In fact, traditional medicine is in the public domain, or it is in the midst of society. Here this study covers information and information policy, the role of governments, organizations involved, policy transformation, and others (Baumgartner \& Jones, 2015).

A study of politics of information needs also to find out how a community reacts to the policies enacted by a government. It includes political antagonism or a politics of contra-flow information (Jordan, 2015).

Another area of the research is traditional medications. In general, there are two streams that serve as the object of research on the treatment, namely medical treatment, that is done in hospitals, local health service center, and clinics using modern medicine; and the second is the traditional flow living in traditional medication centers with different services such as acupuncture, herbs, fracture repair, and others (Novianti et.al., 2017).

Traditional medicine is a treatment that uses tools or materials that are not included in the standard of medical treatment and used as an alternative or complementary to medical treatment. Data show that patients using traditional medicine are more in number than those who visit the doctors. In Australia, $48.5 \%$ of the population use traditional therapy, in France $49 \%$ and Taiwan $90 \%$ of patients received conventional therapy in combination with traditional Chinese medicine. In terms of the types of diseases, the use of traditional therapies in cancer ranges from $9 \%$ to $45 \%$ and the use of traditional therapy in patients with neurological disease varies from $9 \%$ to $56 \%$. The research in China shows that $64 \%$ of patients with progressive cancer use traditional therapy (APECHWG, 2013).

Traditional medicine is an integral part of the culture of society because the concept of illness and the way of treatment is not independent but integrated with cultures. The method of traditional medication is still popular among its supporting community due to its function that is able to meet the requirements related to health. According to the World Health Organization (WHO), countries in Africa, Asia, and Latin America still use traditional medicine as a complement to the primary treatment they receive. Even in Africa, as many as $80 \%$ of the population uses herbal remedies for primary treatment (WHO, 2013). The driving force behind the increasing use of traditional medicines in developed countries are, among others, the longer life expectancy at a time when chronic disease prevalence increases, the failure of modern medicine for certain diseases such as cancer, and the widespread access to information on traditional medicines around the world.

WHO recommends the use of traditional medication including herbal medicines in public health maintenance, disease prevention and treatment, especially for degenerative diseases and chronic cancers. This shows 
WHO support "back to nature," which in this case is more profitable. Therefore, this world organization has issued general guidebooks on traditional medication research. One of the books says that the type of traditional medication developed and grouped into two types: herbal treatment and traditional procedures. Traditional herbal medicine uses original plant materials such as flowers, fruits, roots, or other parts of the plants used for treatment. Medical plant processing is based on finished plant products, or some crop processing products resulting from extraction, fractional dissolution, purification, concentration or physical processing. The second type of traditional medication is therapy. Therapies includes such techniques as acupuncture, chiropractic techniques, osteopathy, manual therapies, qigong, tai $\mathrm{ji}$, yoga, naturopathy, thermal medication and other physical therapies (Novianti et.al., 2017).

Currently, the term of traditional medical treatment is also known as alternative medical treatment. This is because people use such treatment as a replacement of modern medical systems. Traditional medication is intended as a form of treatment service that uses methods, tools, or materials which is not included in modern medical standards (standard medical services) and is used as an alternative or complementary treatment to modern medication (www.MedikaHolistik. com [19/8/2017 ]).

The researchers mentioned above have shown that the traditional medications were effective and even more when they supported with adequate-related information. However, none of the study showed the government's role in giving authorized information called as politics of information. This study is about the search process as well as the accessibility of politics of information on traditional medical practices in the community.

Researchers on traditional medication are great in number. Many studies of herbs or medicinal plants, acupuncture practices, spiritual healings, and so forth grow rapidly. Something new from this research is how the domain of political science, such as public policy, goes into the realm of information, how the government packs the information about their policy to the community, and how does the community both as a customer (consumer) and producer perceives the government regulations, and how they practicing traditional medical treatment.
It includes data searching on how people identify, recognize, record, document, store, transfer, and disseminate information about traditional medication.

The other side of politics of information is its economic dimension. Here, the change in information technology has led to the involvement of certain organizations that perform the massiveness of traditional medication; the emergence of cross-regional cooperation; development and trade cooperation; the presence of consciousness as a unique local treatment group; seeking for harmony in society (Elms \& Low, 2013). In addition, an information literacy study framework can be used here as a basis for the study of politics of information research on traditional medication. In practice, the research process will continue to synergize, both are from the existing approaches and the desired outcomes, adapted to theoretical views and empirical approaches (Hafiar et.al., 2014).

In short, this study is in the context of rural people of West Bandung Regency practicing traditional medicine. The objective is to know how the government implements policies related to traditional medical practices. This is also a study on how the traditional medicinal groups response to public policies on traditional medication.

\section{Research Methods}

This study uses a qualitative approach because it focuses on subjective meanings, understandings, metaphors, symbols, and descriptions of a specific case, i.e. the politics of information of traditional medicinal practices in a community. This approach obtains a detailed and in-depth picture of information about a particular phenomenological social phenomenon. Based on the objectives, this research belongs to the category of descriptive research, ie research that attempts to describe specific details of situations, settings or social relationships that take place within the scope of research subjects (McGann, 2015).

The selection of case studies outlined here because this research starts from the contemporary phenomenon in the field of society that is the midst of various information about traditional medication addressed by government through regulations. Furthermore, this study was conducted to answer the research question of how the 
political activities information (politics of information) related to traditional medication. This is in line with the explanation of Yin (2013) that the case study approach is suitable for research related to research questions on how and why and research to see the contemporary phenomenon. Through case study methods, the presentation of the research results is nothing but the facts found during the research conducted and will be conducted descriptively based on qualitative and quantitative data available.

Techniques used in the process of data collection: (a) Observation. In this technique, the researcher plunge directly to the location of research, conducting exploration and observation of the object research, namely rural communities in West Bandung regency; (b) In-depth interview. This technique is used to seek information from every party interviewed, either the government, the actors of traditional medication, customers, and society in general to know the things required in the study and are considered as the representative for the purposes and objectives of the study; (c) Documentation study. In this technique, researchers try to collect materials in the written form related to research problems correlated with the results of conducted interviews. This documentation is also conducted by describing the traditional treatment mechanisms practiced by treatment providers and other documentary evidences.

\section{Research Result and Discussion}

Kabupaten Bandung Barat (KBB) is a district in West Java Province, Indonesia, as an extension of Bandung regency. It is adjacent to Purwakarta and Subang regencies in the west and north, Bandung regency and Cimahi city in the east, and Cianjur Regency in the west and east. West Bandung regency has populated by about 1.4 million people meaning $42.9 \%$ of the old area of Bandung regency. While the capital city of West Bandung Regency is Ngamprah, located in the area of Bandung-Jakarta road side(www. bandungbaratkab.bps.go.id. [19/8/2017]). The population of KBB is $1,408,550$ people with gender-based proportions consisting of 705,679 male and 702,871 female. The distribution of the population is not even, in which the dense location is in Ngamprah sub-district while the lowest number is in Gununghalu sub-district. The total KBB workforce reaches 447,314 people and is divided into several types of livelihoods such as agriculture and farm laborers with the highest percentage reaching $33.87 \%$. While for industrial Sector reaches $16.53 \%$, trade sector $15.51 \%$, service sector $9.51 \%$ and the other is $24.59 \%$ (www. bandungbaratkab.bps. go.id. [19/8/2017]).

In general, the economic condition of West Bandung Regency is still dominated by industrial sector with a contribution of $41,76 \%$, followed by trade/hotel/restaurant sector equal to $21,22 \%$, and agriculture sector equal to $11,87 \%$. GDP growth per capita at current prices in 2012 reached $10.06 \%$ or Rp. $13,810,500$. While GRDP per capita per constant is 2000 which illustrates the real added value of West Bandung regency residents in 2012 that reached Rp. 5,732,589 or grew by $4 \%$ compared to the previous year. However, it still considered lower than the economic growth in West Java, which is 5.07\% (www.jabar.bps.go.id., 2016). Such conditions also cause the low quality and quantity of health services which is not yet in accordance with expectations and will ultimately affect the level of community welfare.

Health care system is an important part of improving health status. With this health system, the development goals can be achieved effectively, efficiently, and on target. The success of the health care system depends on the various components of the existing funds, supporting facilities and human resources available, in this case, nurses, doctors, radiologists, physiotherapists, nutritionists, and other health teams. The entire field of health services is changing, and none of the changes is faster than in the field of healthcare. Health care is an essential service provided by nurses to individuals, families, and communities who have health problems.

..."The services provided are the effort to achieve health degree as much as possible in accordance with the potential owned in carrying out activities in the field of promotive, preventive, curative, and rehabilitative by using nursing process. Kepmenkes (Health Department) RI No. 128 / Menkes / SK / II / 2004 on Local health states service health center district of UPTD responsible for organizing medical supplies in a working area." (Interview with dr. NL, doctor of West Bandung State Health Institute, 9/6/2017).

Local Health Development Program contains some health development efforts 
established by local health service center and District Health Offices in accordance with the problems, needs, and capabilities of local health service center. In the organizational structure of local health service center, this development program is usually called local specific program. One of them is Traditional Medication, a program of coaching on traditional medical services, traditional healers and the way of traditional medication. Therefore, the traditional treatment is a hereditary treatment, either using herbs, tools (needles, circumcision) or skills (massage) (Interview with YY, Hospital Officer, 9/6/2017).

Each of the programs implemented in local health service center. It is equipped with trained and skilled program implementers, health equipment (service equipment and health consumables), complemented by program implementation guidelines and targets (population target) including recording system (registers recording of services), reports and operational standard of health service program procedures, and also some other equipment such as two-and fourwheeled vehicles. To complete the activity, this local health service center program always gets supervision, evaluation, and guidance from District Health Office (Interview with dr. N.L., 9/6/2017).

The political steps of government's politics of information in West Bandung regency toward the community are done through: 1. Conventional media channels, such as newspapers or radio. 2. Formal communication to formal leaders, i.e government employees, and to the lowest level workers; 3 . Traditional communication, where the government approaches community leaders and informal leaders such as leaders of community organizations. 4 . The website (http://www.bandungbaratkab.go.id/) where there is an open portal for the community to communicate directly with the government. 5. Personal communication channels such as mobile phones, SMS, etc. 6 . Social media channels like Facebook, WhatsApp, etc. (Interview with dr. NL, 9/6/2017).

Health Services Program Development are health development efforts established by local health service center and District Health Offices in accordance with the problems, needs, and capabilities of local health service center. In the organizational structure of local health service center, this development program is usually called Local Specific Program. Some of government programs for traditional medication are coaching programs for traditional medical services, traditional healers, and traditional methods of medication. The traditional medication is defined as a treatment carried out by hereditary, whether by using herbs (herbs), tools (needles, circumcision) and skills (massage) (Interview with dr. N.L., Bandung Barat, 9 / 6/2017).

In a developed society, science is learned through education, both formal and informal. In traditional society, science is acquired more by inheriting it from generation to generation. Thus, as citizens who experience the process of socialization and interaction in the daily relationship and open environment, members of society have the possibility to exchange knowledge and experiences as a legacy of a generation from its predecessor.

This study focuses more on the effort to describe the use of traditional treatment systems, the factors that influence them and the effectiveness of traditional treatment systems provided at local health center.

Alden et al. (2015) modeled the behavior of "treatment options", where crosscultural adaptations contained in the health belief model were used to describe medication decisions. The Young formulation includes four main elements, namely: (1) "gravity", i.e. the severity felt by the individual reference group (the assumption that it exists before feeling sick, ie the common opinion in the group about the severity of the various types of diseases). (2) Knowledge of popular remedies (home remedies), which originate in the cloud referral system (ie if the treatment is unknown, or after testing is found ineffective, then the individual switches to a professional referral system). (3) "Faith" or level of confidence in the success of various treatment options (especially from traditional healing). (4) "Accessibility", including costs and availability of health-care facilities, as well as the "perceived obstacle" in the model of health trust and the "capability factor."

The background factors behind the respondents using traditional treatment services provided by traditional medical centers are due to their treatment using herbal ingredients, and they already believe that the treatment has been done for generations.

..."Besides that, the cost is cheaper than other traditional medication, or cheaper than treatment performed in general 
medication, local health center, or hospital in general." (Interview with KS, a family of a patient, 9/6/2017).

The effectiveness of traditional medication perceived by the respondents is the disease suffered by the patient healed (Interview with ST, patient fractures, $9 / 6 / 2017)$. Likewise, the patient is compatible with the treatment techniques performed in traditional medication and suitable to consume the given drug, suppose it fits with herbals or matches its herbal capsule (Interview with $\mathrm{LH}$, herbal customer, 9/6/2017). It is effective, for the average respondents who have used their traditional medication for almost more than a year. Hence, they suit to the use of traditional medication.

Due to the inadequacy of medical services, supported by the old habit of the community, the existence of traditional medication in West Bandung regency has become so entrenched in the community. This covers many traditional treatment centers. Data for the last three months at the beginning of 2017 shows that there are: massage treatment (351 places); reflexology massage (20 places); bone fractures treatment (75 places); clinic of circumcision (8 places); midwives (424 places); acupressure (1 place); acupuncture (6 places); Chiropractor (3 places); skin and hair beauty treatment (195 places); cupping (57 places); Shiatsu (2 places); inner spiritual energy (91 places); yoga(3 places); local herb medication (141 places); inner cleansing (4 places); Shinse (1 place); Aromatherapy (4 places); and other traditional clinic in 19 places (Source: KBB Health Office, 2017). Those with facilities, some are owned by individual (1057 people), group in 17 places, traditional drug store 9 places; Spa 31 places; and salon 209 places. Then, those who learn and use the traditional medicine plats (toga) are 240 people; Posyandu 72 places; others 92 places. As a result, the number of all is 1727 people/group (Source: KBB Health Office, 2017). In terms of visits, total number of male customers is 1713 and women are 1864 in the last three months of 2016. In terms of types of visits, new visits are about 651 people and regular visits are 2629 people (Source: KBB Dinkes, 2017).

It appears now that (medical) treatment is not just for health issue. It can also be leisure. People go to health places not solely to nourish or heal from illness but also for health-sustaining. It was proven with so many people go to the spa, shiatsu, massage, etc. to get a treatment that is totally different from "medical" treatment.

The politics of information on traditional medication in West Bandung Regency has been successful to enter public awareness. The users of traditional medication get information from many places and media, including social media (Interview with $\mathrm{LH}$, traditional herbal customers, 9/6/2017).

..."In terms of information changes in the community, West Bandung Regency has witnessed the advance of various regulatory on medication, which can lead to changes in social, cultural, and even health technologies. However, many people still use traditional medication because it is cheaper." (Interview with $\mathrm{KS}$, a companion of fracture patients, 9/6/2017).

This economic way of thinking probably is the main reason why traditional medication still preferred among people, especially the villagers. For the sake of economic reason, traditional medical activists could manage the information into their own benefit. For example, the issue that modern medicine is expensive in price. Even if it is cheap, it will in turn bring about some dangerous, fatal diseases, the treatment of which will be very expensive. Alternatively, they propose herbal medicine that is cheap in nature, for it comes from growing plants around us. Also, that the herbs are not dangerous for the health, so that it would not need to spend much money for the treatment. Here traditional medicinal activists take a political step to socialize their products. Positively, they take competitive step by proposing alternative, different product to the modern one. This competitive spirit is something normal in economics (Chamberlin, 1933). Moreover, this step of proposing alternative ways to cure diseases is to propose a solution to a living problem, and this is a way of the politics of information (Baumgartner and Jones, 2015).

In terms of information distribution, all respondents know about traditional medication sources from relatives and friends. This is suitable with the result of Herawati's (2017: 327) who work on AIDS and stated that 'companionship contributes the most to care, support and treatment' of health. However, some also knew it from the mass media and the internet. Respondents also know about the types of traditional medication 
in which the most popular are alternative medication (acupuncture, massage, herbs), energy therapy, and the most respondents' opinion on the notion of traditional medication is the medicinal treatment taken from plants, animals and mineral materials.

Utilization of traditional treatment by the community is mostly for medication and therapy. The type of treatment mostly used by the community is herbal treatment with drinking herbal medication technique according to the type of illness he/she suffered. The types of illnesses ranging from mild to severe, such as flu, rheumatism, diabetes, cancer, kidney failure, down syndrome, malnutrition, obesity, cholesterol, nerve structures, slow speech, prostrate failure, gastrointestinal, and slow brain growth. Furthermore, massage, acupressure, and acupuncture are types of treatment done by respondents to cure the illness suffered without chemical drugs (Interview with $\mathrm{AA}$, a traditional healer, 10/6/2017). Thus, people follow this traditional treatment because it is felt more natural and has no side effects. In addition, it is a fact that the customers felt healed. Therefore, they become loyal to traditional medication. They also follow the procedures of traditional medication voluntarily and happily.

The change of loyalty from modern treatment to traditional one does not happen overnight. Ayub et.al. (2017) quoting Rezal (2016), saying that more often than not patients with chronical diseases seek additional information, even after they went to the doctors. There is a chance to make a trial-and-error patient into a loyal one of traditional medicinal treatment. Having this process means there is a continual, periodic treatment. During the treatment, there is always conversations between the healers and the clients. This is a result of long informational politics happen during contacts between the clients and the healers in the processes of traditional healing service. This is a kind of 'hijacking,' when patients totally surrender themselves to be treated traditionally. For the first time the patients could be just try the treatment, and during this trial the healers could stir the conversation into their own benefit. So, it is a kind of 'hacking' in terms of Tim Jordan (2015).

The next thing happens is self-regulation of the community to decide what kind of treatment suits them. Similarly, as explained by Cameron (2011), individuals are required to be mature enough to determine what is most satisfying for him/her in all his/her condition, since every human has his/her own self-concept on which one is suitable for his/ her condition (Yohana, Hardianti, Mardianti, 2016: 362).

\section{Conclusion}

The article concludes that the politics of information of West Bandung regency government for traditional medication is quite successful. The people of West Bandung Regency mostly welcome the policies that regulate traditional medication and bring the progress in the treatment, both in the hospital and local health service center. The reason of why patients using traditional treatment services provided in traditional medical centers is because the treatment use herbal ingredients (so that it is not dangerously chemical), and have faith in them since it has been done for generations. People also choose the traditional medicine because it is cheaper than the treatment in local health service center or hospital in general. Reasons of effectiveness of traditional medications perceived by the respondents are as follow: it can recover the patients from illness; the patients feel suitable with the treatment techniques and are safe to consume the medication; the patients felt better afterward. Therefore, they become the loyal customers of traditional medication. This development comes from a politics of information performed quite successfully by the traditional healers.

\section{References}

Alden, D.L., J.M. Friend, A.Y. Lee, M. de Vries, R. Osawa \& Q. Chen (2015). Culture and Medical Decision Making: Healthcare Consumer Perspectives in Japan and the United States. Health Psychology. 34 (12), 1133-1144. http://psycnet.apa. org/record/2015-25962-001 [4/4/2018].

APECHWG. (2013). APEC Policy Dialogue on The Development of Medicinal Plant and Traditional Medicine. Medan: APEC Secretariat. (http://www.apechwg. org/meetings/policy-dialogue/policydialogue-2013/policy-dialogue-on-thedevelopment-of-medicinal-plant-andtraditional-medicine-2013) [29/7/2017].

Ayub, Suffian Hadi; Mohammad Rezal Hamzah; Sharipah Nur Mursalina Syed Azmi; Wan Abdul Hayyi Wan Omar; Nor Hafizah Abdullah; Zanirah Wahab; Hishamuddin 
Salim. "Sexual Health Communication Among Youth: A Study of Knowledge and Attitude." Jurnal Komunikasi: Malaysian Journal of Communication. Vol. 33 (4) 2017: 233-248. https://doi.org/10.17576/ JKMJC-2017-3304-15.

Baumgartner, Frank R. and Bryan D. Jones. (2015). The Politics of Information: Problem Definition and The Course of Public Policy in America. Chicago: The University of Chicago Press Books.

Belkin, N.J. \& B.H. Kwasnik. (2017). Using Structural Representations of Anomalous States of Knowledge for Choosing Document Retrieval Strategies. https://www. researchgate. net/publication/221299693_Using_ Structural_Representations_of_ Anomalous_States_of_Knowledge_for_ Choosing_Document_Retrieval_Strategies [4/4/2018].

Brouwer, Natasa \& McDonnell, Claire. (2015). Online Support and Online Assessment for Teaching and Learning Chemistry. In Ingo Eilks and Bill Byers (eds.). Innovative Methods of Teaching and Learning Chemistry in Higher Education. London: RSC Publishing.

Cameron, A. (2011). Impermeable Boundaries? Developments in Professional and Interprofessional Practice. Journal of Interprofessional Care, 25 (1), 53-8.

Chamberlin, Edward. (1933). Theory of Monopolistic Competition. Cambridge, MA: Harvard University Press.

Choo, Chun Wei. (2016). The Inquiring Organization: How Organizations Acquire Knowledge and Seek Information. New York: Oxford University Press.

Elms, Deborah Kay \& Patrick Low. (2013) Global Value Chains in Changing World.

Hafiar, H., Puspitasari, L., \& Anwar, R. K. (2014). Literasi Informasi Media: Studi Kasus Manfaat Media Massa Terhadap Difusi Inovasi Pertanian di Kecamatan Singaparna Kabupaten Tasikmalaya. Edulib, 4(1).

Herawati, Erna. (2017). Warga Peduli AIDS': Community Participation in the HIV and AIDS Response in Bandung. Mimbar, Vol. 33. No. 2nd (December, 2017), pp. 319-328.https://ejournal.unisba.ac.id/ index.php/mimbar/article/view/2439/pdf [4/4/2018].

http://www.medikaholistik.com/ [19/8/2017].

Indonesian Government Act No. 103 on Traditional Health 2014.

Jordan, Tim. (2015). Politics information: Liberation and Exploitation in the Digital Society, London, UK: Pluto Press-Digital Barricades.

KBB Health Office. (2017). Daftar Penyelenggara Kesehatan Tradisional di Kabupaten Bandung Barat. Bandung Barat: Dinkes.

McGann, Marek. (2015). In Ezequiel Di Paolo and Hanne De Jaegher (eds.). Towards an Embodied Science of Intersubjectivity: Widening the Scope of Social Understanding Research. Lausanne, Switzerland: Frontiers Media.

Novianti, E., Anwar, R. K., \& Perbawasari, S. (2017). Access of Village Housewife to Information Technology in Utilizing Family Medicinal Plants-A Case Study of Leuwigoong, Garut Regency, West Java. KnE Social Sciences, 2(4), 170-176.

Sugyati, C., Sjoraida, D. F., \& Anwar, R. K. (2017). Pemahaman Kebijakan Kesehatan Masyarakat Bidang Ibu dan Anak Pada Pelaksana Lapangan di Jawa Barat. Jurnal IImu Pemerintahan: Kajian IImu Pemerintahan dan Politik Daerah, 2(1), 52-60.

WHO. 2013. WHO Traditional Medicine Strategy 2014-2023. Geneva: WHO Press. URL: http://www.who.int/ medicines/publications/traditional/trm_ strategy14_23/en/ [19/8/2017].

w w w. bandungbaratkab.bps.go.id. [19/8/2017].

Yin, Robert K. (2018). Case Study Research: Design and Methods. London: Sage Publications.

Yohana, Nova; Fitri Hardianti; Rina Mardiyanti. (2016). Implications of Self Concept in Communication Behavior of Retarded Children. Mimbar, Vol. 32. No. 2nd (December, 2016), pp. 362-371. https:// ejournal.unisba.ac.id/index.php/mimbar/ article/view/1937/pdf [4/4/2018]. 